\title{
SENSITIZED SPECTROPHOTOMETRIC DETERMINATION OF TRACE AMOUNTS OF COPPER(II) ION USING DIACETYL MONOOXIME IN SURFACTANT MEDIA
}

\author{
M. Ghaedi ${ }^{1 *}$, A. Shokrollahi ${ }^{1}$, F. Ekrampour ${ }^{2}$ and R. Aghaei ${ }^{1}$ \\ ${ }^{1}$ Chemistry Department, Yasouj University, Yasouj, Iran \\ ${ }^{2}$ Chemistry Department, Firouzabad Azad University, Iran
}

(Received December 22, 2008; revised April 28, 2009)

\begin{abstract}
A simple and accurate spectrophotometric method for determination of trace amounts of $\mathrm{Cu}^{2+}$ ions in various real samples has been described. The spectrophotometric determination of trace amount of $\mathrm{Cu}^{2+}$ ion using diacetyl monooxime (DAMO) in the presence of cetyltrimethylammonium bromide (CTAB) as cationic surfactant has been carried out. The Beer's law is obeyed over the concentration range of $0.1-22.0 \mu \mathrm{gmL}^{-1} \mathrm{of} \mathrm{Cu}^{2+}$ ion with the detection limits of $1.3 \mathrm{ngmL}^{-1}$. The influence of type and amount of surfactant, $\mathrm{pH}$, complexation time and amount of ligand on sensitivity of method were optimized. Finally the repeatability, accuracy and the effect of interfering ions on the determination of $\mathrm{Cu}^{2+}$ ion were evaluated.
\end{abstract}

KEY WORDS: Copper(II) determination, Diacetyl monooxime, Cetyltrimethylammonium bromide, Spectrophotometry

\section{INTRODUCTION}

Considering biological research, the role of some trace and ultra-trace elements in the body is very rich and varied. Some of them are essential to life while others are toxic even at very low concentrations [1-3]. Copper has received considerable attention owing to its uses in metallurgy and chemical industries. Moreover, it is an essential constituent of about thirty enzymes and glycoproteins is required for the synthesis of hemoglobin and for some biological processes and also promotes iron absorption from the gastrointestinal system. It is involved in the transport of iron from tissues into plasma, helps to maintain myelin in the nervous system, is important in the formation of bone and brain tissues and is necessary for other many important functions [48]. Among the various analytical techniques available, the use of spectrophotometric method is well establishing routine analytical technique. Specifically, strong copper ion recognition is very important for its determination probably useful for industry and biological application.

Application of micelles in analytical chemistry involves the beneficial alteration of metal ion-ligand complex spectral properties via surfactant association. In recent years spectrophotometric determination in surfactant media as a powerful tool are very useful in analytical application, especially in UV-Visible spectrophotometry [9-12] and fluorescence process. Due to their stability in aqueous solution and transparent optically enhance sensitivity and selectivity $[13,14]$. The utility of surfactants in sensitized spectrophotometry emerged from the various pathway that among them formation of ternary complex with concomitant shift in the analytical wavelength [15-17] and increasing the solubility of insoluble complexes and/or ligands. Therefore, lead to improvement in sensitivity (molar absorptivity) in coincide to red shift (approximately 50-150 nm) [18]. In this view, the selectivity and sensitivity of numerous analytical spectrophotometric-based reactions can be improved using certain surfactants [19, 20].

Oximes reveal certain insecticidal, medical and nematocidal activity such as inhibition of arginase [21]. Some of them are intermediates in the biosynthesis of nitrogen oxide [22], and radiopharmaceuticals in brain tumor diagnostics due to their traversing the blood brain barrier [23]. Certain metallic complexes of furan oximes exhibited cytotoxicity in murine and human

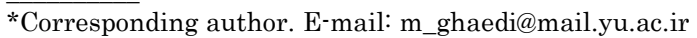


tissue cultured cell lines [24]. Oximes are also used as antidote against organophosphorus poisons [25]. Oxime metal chelates exhibited higher antimicrobial activity than free ligands [26]. Biological functions of oximes and their role in vivo metabolism are evidently dependent on their chelation with metal ions [27]. Chelating ability of oximes is utilized in chemical trace metal analysis, isolation, separation and extraction of various metal ions [29-34].

The purpose of this work is to develop a sensitive and selective spectrophotometric method for trace and ultra-trace $\mathrm{Cu}^{2+}$ ion determination in the presence of CTAB using DAMO. The influence of some analytical parameters including $\mathrm{pH}$, type and amount of surfactant, ligand concentration were examined.

\section{EXPERIMENTAL}

\section{Instrumentation}

A Perkin Elmer Lambada 5, UV-Vis spectrophotometer (USA) was used to measure the absorbance of complex in CTAB media. A $691 \mathrm{pH} / \mathrm{Ion}$ meter (Metrohm, Switzerland) with a combined glass and calomel electrode has been used to adjust the $\mathrm{pH}$. All potentiometric $\mathrm{pH}$ measurements were carried out using a Model 686 Metrohm Titroprocessor equipped with a combined glass-calomel electrode.

\section{Reagent and solution}

All chemicals such as copper(II) nitrate and other cations salts were of the analytical grade and purchased from Merck, Dermastat Company, Germany. $1.0 \%$ (w/v) solutions of all the surfactants were prepared. A surfactant $1 \%(\mathrm{w} / \mathrm{v})$ solution of including sodium dodecyl sulfate (SDS), Triton X-100, cetyltrimethylammonium bromide (CTAB), $n$-dodecytrimethylammonium bromide (DTAB) was prepared by dissolving $1.0 \mathrm{~g}$ of surfactant in $100 \mathrm{~mL}$ volumetric flask while stirring. Carbonate free $\mathrm{KOH}$ solution was standardized with potassium hydrogen phthalate. The $\mathrm{HCl}$ solution was standardized with standard $\mathrm{KOH}$. All the solutions were prepared in doubly distilled deionized water.

\section{Pretreatment of real samples}

Analysis of waste water and spring water sample for determination of $\mathrm{Cu}^{2+}$ ions content was done as follows: $250 \mathrm{~mL}$ of sample was poured in a beaker and $8 \mathrm{~mL}$ of $3 \mathrm{M} \mathrm{HNO}_{3}$ and $3 \mathrm{~mL}$ of $\mathrm{H}_{2} \mathrm{O}_{2}(30 \%)$ were added for the decomposition and elimination of organic compound. While stirring, it was heated to reach its volume to the half of the original volume. After adjustment of samples $\mathrm{pH}$ to desired value the spectrophotometric experiment was carried out. In all the real samples the amount of $\mathrm{Cu}^{2+}$ ion was determined by standard addition method.

Spinach sample was purchased from Firouzabad, Iran. Afterwards, they were taken in small mesh. A $40 \mathrm{~g}$ sample was heated in silica crucible for $3 \mathrm{~h}$ on a hot plate and the charred material was transferred to a furnace for overnight heating at $650{ }^{\circ} \mathrm{C}$. The residue was cooled, treated with $10.0 \mathrm{~mL}$ concentrated nitric acid and $3 \mathrm{~mL} 30 \% \mathrm{H}_{2} \mathrm{O}_{2}$ again and kept in the furnace for $2 \mathrm{~h}$ at the same temperature so that no organic compound traces were left. The final residue was treated with $3 \mathrm{~mL}$ of concentrated hydrochloric acid and $3 \mathrm{~mL}$ of $70 \%$ perchloric acid and evaporated to fumes, so that all the metals change to respective ions. The solid residue was dissolved in water, filtered and by keeping the $\mathrm{pH}$ at 8.5 made up to $25 \mathrm{~mL}$. Then the procedure was applied. Homogenized soil sample of $20 \mathrm{~g}$ or $20 \mathrm{~mL}$ blood sample was weighed accurately and was digested in a $200 \mathrm{~mL}$ beaker in the presence of an oxidizing agent with addition of 10 $\mathrm{mL}$ of concentrated $\mathrm{HNO}_{3}$ and $2 \mathrm{~mL}$ of $70 \% \mathrm{HClO}_{4}$ and heated for $1 \mathrm{~h}$. The content of beaker was filtered through a Whatman No. 40 filter paper and diluted to $250 \mathrm{~mL}$ with distilled water. Then its $\mathrm{pH}$ was adjusted to 8.5 and the procedure was applied. 


\section{Potentiometric measurements}

The procedure employed for the potentiometric $\mathrm{pH}$ measurements was carried out according to our previous publications [35]. In general, an experimental run involved collecting equilibrium data points throughout the entire $\mathrm{pH}$ range, between 2.0 and 11.50 as a function of millimoles standard $\mathrm{KOH}$, added using the piston burette through a fine capillary tip immersed in the solution. In titration, after each addition, the required time was allowed to reach chemical equilibrium. All potentiometric $\mathrm{pH}$ measurements were made on solutions in a $75 \mathrm{~mL}$ doublewalled glass vessel using a Model 686 Metrohm Titoprocessor equipped with a combined glasscalomel electrode and the temperature was controlled at $25.0 \pm 0.1{ }^{\circ} \mathrm{C}$ by circulating water through the double-walled glass vessel, from a constant-temperature bath (home made thermostat). The cell was equipped with a magnetic stirrer and a tightly fitting cap, through which the electrode system and a $10 \mathrm{~mL}$ capacity piston burette were inserted and sealed with clamps and O-rings. Atmospheric $\mathrm{CO}_{2}$ was excluded from the titration cell with a purging steam of purified nitrogen gas. The system was maintained at an ionic strength of $0.10 \mathrm{M}$ by $\mathrm{KCl}$ as a supporting electrolyte. The purity of the ketoximes was also confirmed by potentiometric titration with standard $\mathrm{KOH}$.

Both solutions were titrated potentiometrically with a $\mathrm{CO}_{2}$-free $0.09860 \mathrm{M}$ potassium hydroxide solution. The titrations were performed up to $\mathrm{pH}$ values at which the formation of precipitates began and unstable emf measurements were obtained. From the titration curve of the first solution the acidic protonation constants of the ligands and from the second titration curve the formation constants of complexes were evaluated using the BEST program described by Martell and Motekaitis [36].

\section{RESULTS AND DISCUSSION}

Although, the oximes are widely used in various analytical processes for preconcentration, extraction and spectrophotometric determination of metal ions, little attention has been paid to complexation and distribution equilibrium related to these systems. BEST program has been used for the potentiometric and solution studies and calculation of acidic and stability constant of other ligands with some transition and heavy metal ions as reported in our previous publications [37-41].

The $\mathrm{pH}$ measurement method for investigating the dependency of complexation to $\mathrm{pH}$ for calculating protonation constants of DAMO and stability constants of respective complexes with $\mathrm{Cu}^{2+}$ ions was carried out according to experimental section. In this regard, a solution containing $1 \mathrm{mmol}$ of ligands was placed in the cell and the required amount of $\mathrm{KCl}$ (from a $0.50 \mathrm{M}$ stock solution $), \mathrm{HCl}(0.10 \mathrm{M})$ were added. Finally, the required amount of doubly distilled deionized water was added to the cell to a total volume of $50 \mathrm{~mL}$. The second solution contains the same amounts of component plus about $0.264 \mathrm{mmol}$ of $\mathrm{Cu}^{2+}$ ion and doubly distilled deionized water was added to the same total volume.

The protonation constants of DAMO at similar condition of experimental variables including ionic strength and temperature in binary systems were obtained. The titration data for ligands in the absence and presence of $\mathrm{Cu}^{2+}$ ion were obtained and $\mathrm{pH}$ versus volume plots is shown in Figure 1. In DAMO structure, first protonation constant $\left(\log \mathrm{K}_{1}=9.56\right)$ is attributed to oxime proton, while the second with (small value of $\log \mathrm{K}_{2}=1.94$ ), belongs to the protonation constant of the hydrogen which attached to nitrogen of oxime group that stabilized by interamolecular hydrogen bonding with carbonyl group.

The species distribution curve of DAMO in presence of $\mathrm{Cu}^{2+}$ ion is shown in Figure 2. It was observed the one protonated species MLH with the most abundant $\mathrm{pH}$ (2-2.7), ML species at $\mathrm{pH}=5.7$ and $\mathrm{ML}_{2}$ at $\mathrm{pH}>8.8$. The results obtained from this figures indicate that $\mathrm{ML}_{2}$ as the 
species with high stability formed at $\mathrm{pH}>8.8$. Overall stability constants, the protonation constant of DAMO and $\mathrm{Cu}^{2+}$ - DAMO binary systems are given in Table 1 .

Due to the presence of carbonyl and oxime nitrogen in DAMO structure it act as bidentate ligand and form a five-member chelate ring with $\mathrm{Cu}^{2+}$ ion in binary and ternary systems and no polynuclear complexes between some $\alpha$-oxooximes with $\mathrm{Cu}^{2+}$ ion has been observed. The distribution diagram of the resulting $\mathrm{Cu}^{2+}$ complexes is shown in Figure 2. According to corresponding distribution diagram, species are $\mathrm{CuL}$ and $\mathrm{CuL}_{2}$ which formed at higher $\mathrm{pH}$ and protonated species involve $\mathrm{CuLH}$ is formed at low $\mathrm{pH}$ ranges.

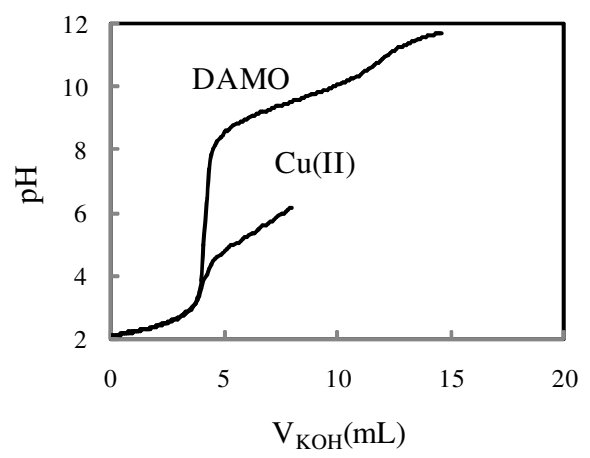

Figure 1. Equilibrium $\mathrm{pH}$ titration curves of DAMO in the absence and presence of $\mathrm{Cu}^{2+}$ ions.

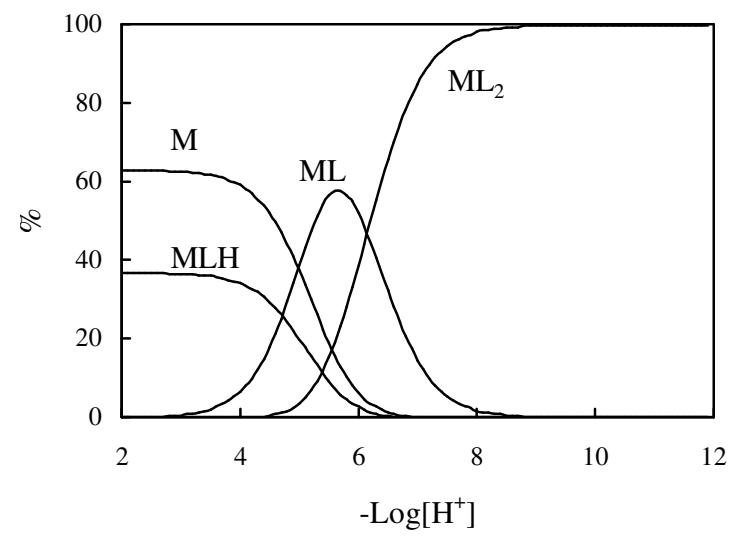

Figure 2. Distribution diagram of DAMO/Cu ${ }^{+2}$ system.

Table 1 . Overall stability constants in DAMO/ $\mathrm{H}^{+} / \mathrm{Cu}^{2+}$ system.

\begin{tabular}{|l|c|c|c|c|}
\hline System & $\mathrm{M}$ & $\mathrm{L}$ & $\mathrm{H}^{+}$ & $\log \beta$ \\
\hline \multirow{2}{*}{ DAMO } & 0 & 1 & 1 & 9.51 \\
\cline { 2 - 5 } & 0 & 1 & 2 & 11.45 \\
\hline $\mathrm{Cu}^{2+}$-DAMO & 1 & 1 & 0 & 6.30 \\
& 1 & 2 & 0 & 11.02 \\
\cline { 2 - 5 } & 1 & 1 & 1 & 11.56 \\
\hline
\end{tabular}

It is occurs to us that due to incorporation of nitrogen and oxygen atoms as $\sigma$-donor and $\pi$ acceptor and high density of $\pi$-electrons in the ligand structure through the ion-dipole

Bull. Chem. Soc. Ethiop. 2009, 23(3) 
interaction between oxygen and $\mathrm{Cu}^{2+}$ ion and $\sigma$-donation $\pi$-acceptance between them a rapid quantitative complexation occur. Due to these types of interaction the rate of the complex formation is high and reversible. It seems that the DAMO be useful for spectrophotometric determination of trace amount of $\mathrm{Cu}^{2+}$ ion.

\section{Absorption spectra of $\mathrm{Cu}(\mathrm{ACMO})_{2}$ in $\mathrm{CTAB}$ media}

Regarding the increase in sensitivity of complexation of $\mathrm{Cu}^{2+}$ ion with DAMO in the presence and absence of surfactant (Figure 3), it must be concluded that the addition of surfactant is necessary to increase the figures of merit of proposed method. Therefore, a set of similar solutions containing $5.0 \mu \mathrm{gmL}^{-1}$ of $\mathrm{Cu}^{2+}$ ion, $0.09 \mathrm{mM}$ DAMO (in the presence and absence of $6.0 \mathrm{mM}$ CTAB have been prepared and spectrophotometric investigation has been conducted. Then, absorption spectra of desired complex in the presence and absence of surfactant CTAB were obtained. Experiments in surfactant media have higher sensitivity no use of organic solvent, short time with simplicity.

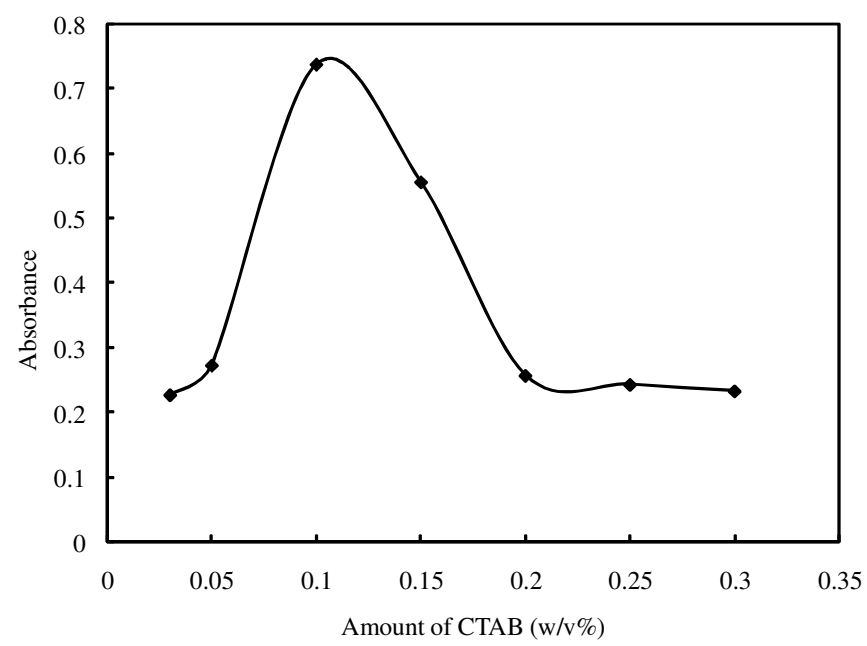

Figure 3. Effect of CTAB concentration on sensitivity at optimum condition, $5 \mathrm{mM}$ DAMO, 5.0 $\mu \mathrm{gmL}^{-1} \mathrm{Cu}^{2+}$ ion, $\mathrm{pH}$ 8.0.

\section{Effect of type of surfactant on sensitivity}

The desired complex and diacetyl monooxime has low solubility in aqueous media, and sensitivity of its complex in the absence of surfactants is low. To improve the sensitivity, the effect of type and concentration of surfactants on the reaction were examined. To ensure the effect of types of surfactants, Triton X-100 and Brij 58 as nonionic, sodium dodecyl sulfate (SDS) as anionic surfactant and cetyltrimethylammonium bromide (CTMAB) and $n$ dodecytrimethylammonium bromide (DTMAB) as cationic surfactant on the absorbance of above mention complex were studied. As shown in Table 2, $0.1(\% \mathrm{w} / \mathrm{v})$ CTAB media, the calibration curve with high sensitivity and red shift could be constructed and its slope was approximately 1.5 times more than in the absence of surfactant. In other media spectra can be obtained with lower sensitivity, so CTAB was selected for further studies. This observation that in the presence of cationic surfactant, method had high sensitivity suggests that complex interacts with the CTAB as cationic surfactant, hydrophobic solvation of the chelate cause increase in solubility in addition to electrostatic interaction. This is emerged from the fact that 
surfactant only lead to aggregation of complexes and increase in sensitivity. It seems that ACMO combines with $\mathrm{Cu}^{2+}$ ion to form a polar complex, and the complexes are extracted instantaneously into the local polar environment of micelle of cationic surfactant. A $0.1 \%(\mathrm{w} / \mathrm{v})$ of CTAB has been used for further studies. Therefore, addition of surfactant for increasing sensitivity is necessary.

Table 2. Effect of type of surfactant on spectra and sensitivity, $5 \mu \mathrm{gmL}^{-1} \mathrm{Cu}^{2+}$ ion, $5 \mathrm{mM}$ DAMO, pH 8.0, $0.1(\% \mathrm{w} / \mathrm{v})$ surfactant.

\begin{tabular}{|l|l|l|l|l|l|l|}
\hline Surfactant & DTAB & X-114 & CTAB & X-100 & SDS & No surfactant \\
\hline Absorbance & 0.667 & 0.623 & 0.702 & 0.667 & 0.501 & 0.59 \\
\hline
\end{tabular}

Effect of $p H$

Complexation between copper ion and DAMO depends on the $\mathrm{pH}$ at which complex formation occurs. $\mathrm{pH}$ plays a unique role on metal-chelate formation and subsequent determination. The influence of $\mathrm{pH}$ on the method sensitivity has been carried out by conducting a set of similar experiments by changing the $\mathrm{pH}$ of aqueous solution of sample in the range of 2.0 to 9.0 and the results are shown in Figure 4. It was found, at $\mathrm{pH}$ of 8.0 maximum sensitivities were achieved. Therefore, a $\mathrm{pH}$ of 8.0 was selected for subsequent work. In acidic medium, a weak complexation occurs, which is explained by competition between metal ions and proton for the binding to ligand. On the other hand by increasing the $\mathrm{pH}$, the potential of active sites of ligand for metal ion binding and consequently the metal ions uptake were increased. The complexation capacities increased with increasing $\mathrm{pH}$, reaching plateau values at around $\mathrm{pH} 8.0$ (Figure 4). The complexation of metal ion beyond the $(\mathrm{pH}>8)$ is attributed to the formation of metal hydroxide species such as soluble $\mathrm{M}(\mathrm{OH})^{+}$and/or insoluble precipitate of $\mathrm{M}(\mathrm{OH})_{\mathrm{n}}$.

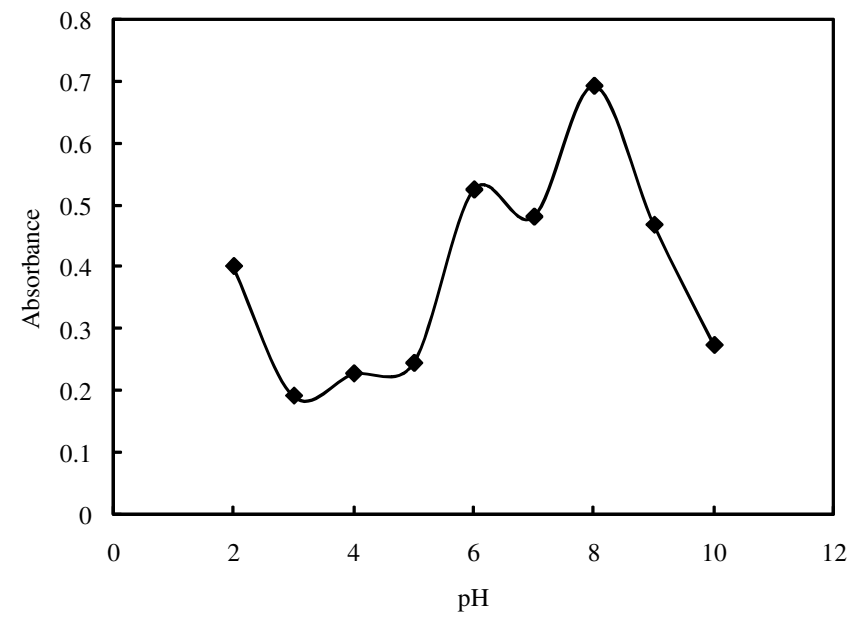

Figure 4. Effect of $\mathrm{pH}$ on sensitivity of $\mathrm{Cu}^{2+}$ ion in micellar media, $5 \mathrm{mM}$ DAMO, $5.0 \mu \mathrm{gmL}^{-1}$ $\mathrm{Cu}^{2+}$ ion, $0.1(\% \mathrm{w} / \mathrm{v}) \mathrm{CTAB}$.

Effect of DAMO concentration on sensitivity

Bull. Chem. Soc. Ethiop. 2009, 23(3) 
The concentration of DAMO has a large effect on the absorbance of the method. For this evaluation, a set of similar experiments at $5.0 \mu \mathrm{gmL}^{-1}$ of copper ion in $\mathrm{pH} 8$ and $0.1 \%(\mathrm{w} / \mathrm{v})$ of $\mathrm{CTAB}$ and various amount of DAMO were conducted and respective results are shown in Figure 5. As it can be seen, the maximum absorbance was observed in $5 \mathrm{mM}$ of DAMO (a 20 fold excess of ligand regardless of $\mathrm{Cu}^{2+}$ ion concentration within the linear range). So we added ACMO more than 20 times of $\mathrm{Cu}^{2+}$ concentration to reduce fluctuation in measurement of absorbance.

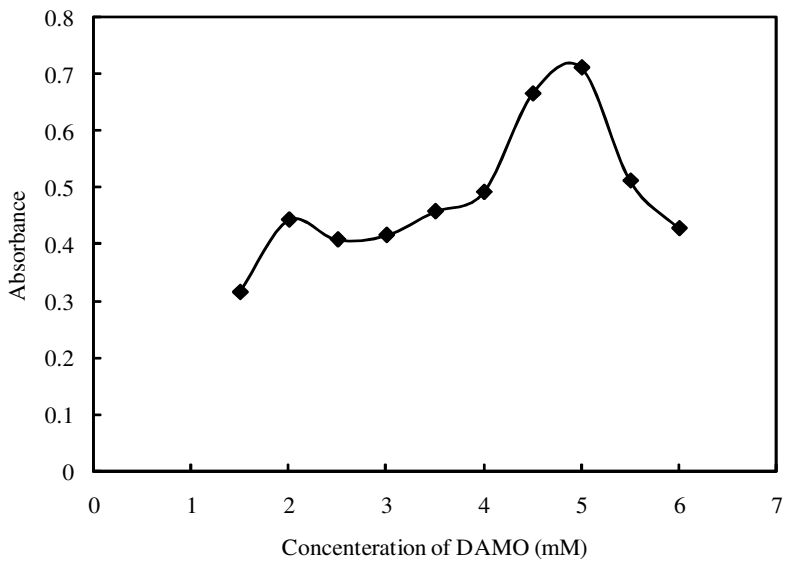

Figure 5. Effect of DAMO concentration $(\mathrm{mM})$ on sensitivity at optimum conditions, $5.0 \mu \mathrm{g}$ $\mathrm{mL}^{-1} \mathrm{Cu}^{2+}$ ion, $0.1(\% \mathrm{w} / \mathrm{v}) \mathrm{CTAB}, \mathrm{pH}$ 8.0.

\section{Interference effect}

In the spectrophotometric determinations of metal ions, levels of diverse ions are important problems. In order to assess the possible analytical applications of the recommended procedure, the effect of some foreign ions which interfere with the determination of trace amounts of the copper ions or/and often accompany the analyte ions in various real environmental samples was examined with the optimized conditions. Therefore various amount of interfering ion were added to $1 \mu \mathrm{gmL}^{-1}$ of $\mathrm{Cu}^{2+}$ ion, copper ion was determined in the mixture and results are given in Table 3. Results display that among the ions studied, some ion could be tolerated up to the $\mathrm{mg}$ level. Tolerable limit was defined as the highest amount of foreign ions that produced an error not exceeding $5 \%$ in sensitivity of methods.

Table 3. Evaluating the tolerance limit of method for interference.

\begin{tabular}{|l|l|}
\hline Interfering ion & Interfering ion to copper weight ratio \\
\hline $\mathrm{Ag}^{+}, \mathrm{Hg}^{2+}, \mathrm{Ni}^{2+}, \mathrm{Co}^{2+}, \mathrm{Zn}^{2+}$ & 50 \\
\hline $\mathrm{Fe}^{2+}, \mathrm{Fe}^{3+}$ & 100 \\
\hline $\mathrm{K}^{+}, \mathrm{Ba}^{2+}, \mathrm{Mg}^{2+}$ & 500 \\
\hline $\mathrm{NO}_{3}^{-}, \mathrm{CH}_{3} \mathrm{COO}^{-}, \mathrm{Cl}^{-}, \mathrm{Br}^{-}$ & 500 \\
\hline
\end{tabular}

Calibration curve and detection limit

Bull. Chem. Soc. Ethiop. 2009, 23(3) 
A calibration plot for the determination $\mathrm{Cu}^{2+}$ ion was prepared according to the general procedure under the optimum conditions developed above from the sensitized spectrophotometric method with various concentration of this ion. The dynamic range of $\mathrm{Cu}^{2+}$ ion was $0.1-22.0 \mu \mathrm{gmL}^{-1}$ with correlation coefficient $\left(\mathrm{R}^{2}\right)$ of 0.9998 which show the good linearity of calibration curve. Based on the signals of ten blank solutions and the slope of calibration curve, it was found that the detection limit was $1.3 \mathrm{ng} \mathrm{mL}^{-1}$.

\section{Accuracy and applications}

In order to assess the applicability of the method to real samples, with different matrices containing varying amounts of a variety of diverse ions, it was applied for the determination of trace amount of $\mathrm{Cu}^{2+}$ ion in different matrices such as vegetable, blood, soil and river water. Spiking experiments using standard addition method checked the reliabilities. The percent of recoveries and relative standard deviation for each element in spiked vegetable, water samples are given in Table 4. As seen, the results of three analyses of each sample show that, in all cases, the ions recoveries are almost quantitative with a low RSD.

Table 4. Recovery studies of trace metal ions from some real samples.

\begin{tabular}{|l|c|c|c|c|}
\hline Sample & $\begin{array}{c}\text { Added } \\
\mu \mathrm{g} \mathrm{g}^{-1}\end{array}$ & $\begin{array}{c}\text { Found } \\
\mu \mathrm{g} \mathrm{g}^{-1}\end{array}$ & $\begin{array}{c}\text { RSD } \\
\%\end{array}$ & $\begin{array}{c}\text { Recovery } \\
\%\end{array}$ \\
\hline Spinach & 0 & 78.6 & 2.7 & --- \\
& 100 & 180.1 & 2.0 & 101.5 \\
\hline Soil & 0 & 0.284 & 3.0 & --- \\
& 0.4 & 0.693 & 2.1 & 102.3 \\
\hline Blood & 0 & 0.162 & 2.5 & ---- \\
& 0.2 & 0.368 & 2.0 & 103.0 \\
\hline River water & 0 & 0.064 & 2.6 & ---- \\
& 0.040 & 0.103 & 2.0 & 102.5 \\
\hline
\end{tabular}

\section{CONCLUSIONS}

An efficient and sensitive method for the determination of trace amount of $\mathrm{Cu}^{2+}$ ion has been developed by using diacetyl monooxime. The method has advantages such as high selectivity and sensitivity, low detection limit, simplicity, low cost and no need for extraction using organic harmful solvent. The proposed method has been successfully applied to the determination of copper ion at trace level. The low RSD of real sample analysis is an indication of method reliability for the real samples analysis.

\section{REFERENCES}

1. Ghaedi, M.; Ahmadi, F.; Baezat, M.R.; Safari, J. Bull. Chem. Soc. Ethiop. 2008, 22, 331.

2. Ghaedi, M.; Amini, M.K.; Rafi, A; Gharaghani, S.; Shokrolahi, A. Ann. Chim. 2005, 95, 457.

3. Ghaedi, M.; Fathi, M.R.; Marahel, F.; Ahmadi, F. Feressen. Environm. Bull. 2005, 14, 1158.

4. Farajzadeh, M.A.; Bahram, M.; Zorita, S.; Mehr, B.G. J. Hazard. Matar. 2009, 161, 1535

5. Panahi, H.A.; Karimi, M.; Moniri, E.; Soudi, H. African J. Pure Applied Chem. 2008, 2, 96.

6. Lemos, V.A.; dos G.; Novaes, S.; de Carvalho A.L., E.M. Gama, A.G. Santos Environ. Monit. Assess. 2009, 148, 245.

7. Soylak, M.; Dogan, M. Anal. Lett. 1996, 29, 635.

8. Tuzen, M.; Önal, A.; Soylak, M. Bull. Chem. Soc. Ethiop. 2008, 22, 379. 
Spectrophotometric determination of $\mathrm{Cu}$ (II) using diacetyl monooxime in surfactant media 345

9. Tuzen, M; Uluozlu, O.D.; Usta, C.; Soylak, M. Anal. Chim. Acta 2007, 581, 241.

10. Tuzen, M.; Soylak, M. J. Hazard. Mater. 2009, 162, 724.

11. Soylak, M.; Tuzen, M. J. Hazard. Mater. 2006, 138, 195.

12. Soylak, M; Tuzen, M; Souza, A.S.; Korn, M.d.G.A.; Ferreira, S.L.C. J. Hazard. Mater. 2007, 149, 264.

13. Fujita, Y.; Mori, I.; Yamaguchi, T.; Hoshino, M.; Shigemuri, Y.; Shimano, M. Anal. Sci. 2001, 17, 853 .

14. Lee, S.K.; Choi Bull, H.S. Korean Chem. Soc. 2001, 22, 463.

15. Gao, H.W. Braz. J. Chem. Soc. 2002, 13, 78.

16. Park, C.I.; Huang, H.Z.; Cha Bull, K.W. Korean Chem. Soc. 2001, 22, 84.

17. Choi, Y.S.; Choi Bull, H.S. Korean Chem. Soc. 2003, 24, 222.

18. a) Shokrollahi, A.; Ghaedi, M.; Niband, M.S.; Rajabi, H.R. J. Hazard. Mater. 2008, 151, 642; b) Ghaedi, M.; Daneshfar, A.; Shokrollahi, A.; Ghaedi, H.; Arvin Pili, F. Ann. Chim. 2007, 97, 971.

19. Ghaedi, M. Spectrochim. Acta A 2007, 66, 295.

20. Teixeira, L.S.G.; Costa, A.C.S.; Ferreira, S.L.C.; Freitas, M.D.L.; Carvalho, M.S.D. J. Braz. Chem. Soc. 1999, 10, 519.

21. Fan, Y.X.; Zheng, Y.X. Anal. Chim. Acta 1993, 281, 353.

22. Pavon, J.L.P.; Cordero, B.M. Analyst 1992, 117, 215.

23. a) San Andres, M.P.; Marina, M.L.; Vera, S. Talanta 1994, 41, 179; b) San Andres, M.P.; Vera, S. J. Liq. Chromatgr. Relat. Technol. 1996, 19, 799.

24. a) Jin, G.; Zhu, W.; Jiang, W.; Xie,B.; Cheng, B.; Analyst 1997, 122, 263; b) Pelizzetti, E.; Pramauro, E. Anal. Chim. Acta 1985, 169, 1; c) Hernandez, J.; Moreno, B.; Prez, J.L.; Cerda, J. Inorg. Chim. Acta 1987, 140, 245.

25. Custot, J.; Boucher, J.L.; Vadon, S.; Guedes, C.; Dijols, S.; Delaforge, M.; Mansuy, D. J. Bio. Inorg. Chem. 1996, 1, 73.

26. Mansuy, D.; Battioni, P.; Battioni, J. Euro. J. Biochem. 1989, 184, 267.

27. Blower, P.J. Trans. Metal Chem. (Weinheim) 1998, 23, 109.

28. Hall, I.H.; Lee, C.C.; Ibrahim, G.; Khan, M.A.; Bouet, G. Appl. Org. Chem. 1997, 11, 565.

29. Ghaedi, M., Asadpour, E., Vafaie, A. Spectrochim. Acta A 2006, 63, 182.

30. Mehta, B.H.; Nagarkoti, B. Asian J. Chem. 2002, 14, 103.

31. Patel, P.S.; Ray, A.; Patel, M.M. Proc. Indian Acad. Sci.-Chem. Sci. 1992, 104, 471.

32. Ramachandra Ready, B.; Radhika, P.; Rajesh Kumar, J.; Neela, D.; Priya, Rajgopal, K. Anal. Sci. 2004, 20, 345.

33. Jadhav, S.B.; Tandel, S.P.; Malve, S.P. Talanta 2001, 55, 1059.

34. Ghaedi, M.; Asadpour, E.; Vafaie, A. Spectrochim. Acta A 2006, 63, 182.

35. Ghasemi, J.; Shokrollahi, A. Iranian J. Chem. Chem. Engin. Internat. 2001, 20, 22.

36. Martell, A.E.; Motekaitis, R.J. Determination and Use of Stability Constants, 2nd ed., VCH: New York; 1992.

37. Ghaedi, M.; Shokrollahi, A.; Rajabi, H.R. Ann. Chim. 2007, 97, 823.

38. Shokrollahi, A.; Ghaedi, M.; Rajabi, H.R. Spectrochim. Acta A 2008, 71, 655.

39. Ghaedi, M.; shokrollahi, A.; Ahmadi, F.; Rajabi, H.R.; Soylak, M. J. Hazard. Mater. 2008, $150,533$.

40. Karimi, H.; Ghaedi, M.; Shokrollahi, A.; Rajabi, H.R.; Soylak, M. J. Hazard. Mater. 2008, $151,26$.

41. Shokrollahi, A.; Ghaedi, M.; Ghaedi, H. J. Chinese Chem. Soc. 2007, 54, 933. 